\title{
DIGITAL TRANSFORMATION IN HUMAN RESOURCES MANAGEMENT: INVESTIGATION OF DIGITAL HRM PRACTICES OF BUSINESSES
}

DOI: 10.17261/Pressacademia.2020.1282

RJBM- V.7-ISS.3-2020(7)-p.188-200

\section{Selma Kilic Kirilmaz}

Sakarya University, School of Applied Sciences, International Trade and Logistics, Sakarya, Turkey. skirilmaz@subu.edu.tr., ORCID: 0000-0002-8478-1910

Date Received: June 12, 2020

Date Accepted: September 10, 2020

To cite this document

Kirilmaz, S. K., (2020). Digital transformation in human resources management: investigation of digital hrm practices of businesses. Research Journal of Business and Management (RJBM), V.7(3), p.188-200.

Permanent link to this document: http://doi.org/10.17261/Pressacademia.2020.1282

Copyright: Published by PressAcademia and limited licensed re-use rights only.

\begin{abstract}
Purpose- This study was carried out to determine the effects of changes in the digital world on Human Resources Management Practices. Methodology- Content analysis method, which is a qualitative research method, was used in the research.

The data were obtained from secondary data obtained from interviews with Business executives and HR managers. In order to reach these interviews, "Digital Human Resources Management", "Digital Transformation HR", "Digital Transformation Human Resources Management", "Digital Business" titles were searched and interviews suitable for the research were included in the study.

In this way, 16 (sixteen) companies formed the sample of the research. All data obtained from the search has been classified and analysed. Findings- As a result of the research, it is seen that businesses have carried many HRM Practices to digital environment. Among the digital HRM Practices that businesses use the most; Using chatbots, receiving job applications using QR code, mobile HRM applications, making data-based analysis using the dashboard, using artificial intelligence in recruitment processes.

Conclusion- It has been observed that the enterprises examined within the scope of the research closely follow the digital transformation in HRM and all businesses that want to gain competitive advantage should be closely follow this digital transformation in HRM.
\end{abstract}

Keywords: Digital HR, digital transformation, human resources management, digitalization, industry 4.0.

JEL Codes: M12, M15, M54

\section{INSAN KAYNAKLARI YÖNETIMINDE YAŞANAN DiJITAL DÖNÜŞÜM: IŞLETMELERIN DiJITAL IKY UYGULAMALARININ ARAŞTIRILMASI}

\section{ÖZET}

Amaç- Bu çalışma, dijital dünyada yaşanmakta olan değişikliklerin İnsan Kaynakları Yönetimi Uygulamalarına olan etkilerini belirlemek amacıyla yapılmıştır.

Yöntem- Araştırmada nitel bir araştırma yöntemi olan içerik analizi yöntemi kullanılmıştır. Veriler, İşletme yöneticileri ve í yöneticileri ile yapılan röportajlardan elde edilen ikincil verilerden elde edilmiştir. Söz konusu röportajlara ulaşmak için "Dijital İnsan Kaynakları Yönetimi”, "Dijital Dönüşüm IK", "Dijital Dönüşüm İnsan Kaynakları Yönetimi", "Dijital Iş̧letme” başlıkları ile aramalar yapılmıştır ve araştırmaya uygun olan röportajlar çalışma kapsamına alınmıştır. Bu sayede 16 (onaltı) işletme araştırmanın örneklemini oluşturmuştur. Arama sonucunda elde edilen tüm veriler sınıflandırılıp analiz edilmiştir.

Bulgular- Araştırma sonucunda, işletmelerin bir çok IKY uygulamasını dijital ortama taşıdıkları görülmüştür. Işletmelerin en çok kullandıkları dijital IKY uygulamaları arasında; Chatbotların kullanılması, iş başvurularının QR kod kullanılarak alınması, mobil ikY uygulamaları, dashboard kullanarak veriye dayalı analizler yapııması, işe alım süreçlerinde yapay zekanın kullanılması sayılabilir.

Sonuç- Araştırma kapsamında incelenen Işletmelerin IKY alanındaki dijital dönüşümü yakından takip ettikleri görülmüştür ve rekabet avantajı sağlamak isteyen tüm işletmelerin bu dönüşümü yakından takip etmeleri gerektiği söylenebilir.

Anahtar Kelimeler: Dijital ǐk, dijital dönüşüm, insan kaynakları yönetimi, dijitalleşme, endüstri 4.0.

JEL Kodları: M12, M15, M54 


\section{GíRiş}

Dijitalleşme, günümüzde Endüstri 4.0 ile birlikte işletmeleri en çok etkileyen konulardan birisidir. Dijitalleşme işletmelerin mal ve hizmet üretiminde dijital teknolojilerden faydalanmasını ifade etmektedir. Dijital teknolojiler işletmelere maliyet ve zaman tasarrufu sağlamakta ve bu sayede işletmeler rakiplerine karşı rekabet avantajı kazanabilmektedir.

Yaşanan dijital dönüşümden en çok etkilenen işletme fonksiyonlarından birisi de İnsan kaynakları yönetimidir. İnsan odaklı bir yaklaşımla personel yönetiminden insan kaynakları yönetimine geçilmiş, bu anlayışa stratejik bakış eklenerek stratejik insan kaynakları yaklaşımı hakim olmuştur. Ancak günümüzde teknolojinin ilerlemesi ile birlikte insan kaynakları yönetiminde dijitalleşme oldukça önemli bir hale gelmiştir.

İnsan kaynakları yönetimi alanında kullanılan dijital teknolojiler arasında yapay zekalı robotların mülakatlar gerçekleştirmesi, Chatbotların kullanımı, bordro, izin, özlük bilgilerinin dijital ortama taşınması, eğitimlerin online olarak yapılması, iş başvurularında QR kod kullanımı, tüm IK fonksiyonlarının mobil uygulamalara taşınması ve buradan takibin yapılması, online performans ölçümü ve anında geri bildirim yapılması, kariyer planlarının dijital ortamda yapılması sayılabilir.

Dijitalleşmenin insan kaynakları uygulamaları açısından işletmeler için bir çok avantajı bulunmaktadır. Bunlardan ilki maliyet tasarrufu sağlıyor olmasıdır. Dijitalleşen ik uygulamaları sayesinde kağıt vb tasarrufu sağlanması işletmelerin maliyetlerini azaltmaktadır. Bir diğer avantajı ise zaman tararufu sağlamasıdır. Dijital uygulamalarla, mauel olarak yapılan işlemler için harcanan zamandan çok daha hızlı bir şekilde işlemler yapılabilmektedir. Son olarak, dijital uygulamalar işletmelerin daha esnek çalışabilmesine olanak tanımaktadır. Yapılan bu çalışmada işletmelerin, dijital insan kaynakları uygulamalarını ne şekilde kullandıkları ve dijitalleşme düzeyleri araştırılmıştır.

Dijital dönüşüm ve insan kaynaklarına etkilerinin belirlenmesine yönelik olarak yapılan bu araştırmada ilk olarak Kavramsal temeller üzerinde durularak, dijitalleşme ve insan kaynakları kavramları ele alınmıştır. Daha sonra Yöntem bölümünde; Verilerin Toplanması, Örneklem, Araştırmanın Amacı ve Önemi konularında değinilmiştir. Bulgular kısmında araştırmadan elde edilen buldular açıklanmıştır. Sonuç kısmında ise araştırmadan elde edilen sonuçlar değerlendirilmiştir.

\section{LITERATÜR INCELEMESI}

Insan kaynakları yönetimi, şirketlerin çalışanlarının becerilerini, yeteneklerini, davranışlarını ve organizasyon hedeflerine ulaşma konusundaki tutumlarını şekillendirebilecekleri temel kaynaklardan biri olarak kabul edilmektedir. Yöneticiler, İ uygulamalarını buna göre tasarlayarak çalışanlar arasında yenilikçiliği, bilgi yönetimi kapasitesini ve öğrenmeyi geliştirebilmektedir. Bu sebeple, İnsan Kaynakları uygulamaları bilgi temelli bir ekonomide kritik bir öneme sahip olmaktadır (Çiftçioğlu, Mutlu ve Katırcıŏlu, 2019: 45).

Dijitalleşme en temel anlamıyla otomasyonu ifade etmektedir (Seçer, 2017: 763). Dijital dönüşüm, bir şirketteki tüm düzeylerde köklü değişiklikler içerir ve süreçleri, kaynakları ve iç ve dış paydaşları etkiler. Bu değişiklikleri desteklemek için, alışkanlıkları yeni gereksinimlere uyarlamak ve yeni, daha uygun çalışma yolları bulmak için bir kuruluş içinde dijital yeteneklerin uygulanması gerekmektedir. (Som, 2019: 2).

1990'ların ortalarında İnsan Kaynakları Yönetimi departmanları, istihdam, seçim, eğitim, performans ve tazminat ile ilgili hedefleri gerçekleştirmek için kurumsal kaynak planlama (ERP) sistemleri veya web tabanlı sistemler kullanmaya başlamıştır. 2000'li yıllardaki internet kullanımındaki artış nedeniyle kuruluşlar e-ikY uygulamaları kapsamını genişletmeye başladı (Celep ve Afacan Findıklı, 2018: 65).

Teknolojik ilerlemelerle birlikte sanayinin gelişmesi "Dijital Çağ" hatta "Dijital Devrim" olarak adlandırılan yeni bir dönemi başlatmıştır (Yalçın Kayıkçı ve Kutluk Bozkurt, 2018: 55). Dijitalleşme; marka ve kurumların verimliliğine, sürdürülebilirliğine ve kârlılığına pozitif bir etki kazandırmanın yanı sıra insan kaynakları süreçlerinde de dönüşümü tetiklemektedir. Teknoloji hızını artırdıkça, dijitalleşen dünya iş hayatının kurallarını da değiştirmektedir. Bu bağlamda, elde tutulması zor olan yetenekli çalışanları elinde tutmak isteyen, yönetici-çalışan arasında şeffaf bir bağ kurmayı amaçlayan örgütlerin insan kaynakları uygulamalarını mobil ve dijital bir platformda yapılandırması gerekmektedir (Çiftçioğlu, Mutlu ve Katırcıoğlu, 2019: 45).

Son on yılda, dijital teknolojiler neredeyse her sektördeki işletmeleri etkiledi ve bazı iş modellerini eskimiş hale getirdi ve yeni dijital ekonomide gelişmek isteyen kuruluşlar için zorunlu hale geldi (Som, 2019: 2). Veri yönetimi için bir destek sistemi olarak tanımlanan teknoloji - veri ve bilgi işleme, depolama, iletim ve İnternet iletişimi, Bilgi ve iletişim Teknolojileri (BIT), tanık olduğumuz olağanüstü teknolojik evrimin bir sonucu olarak zaman içinde büyük ölçüde değişmiştir (Garbelli, 2020: 27). 
Endüstri 4.0 ile Dijital ik yakından ilişkilidir. Endüstri 4.0; emek verimliliğinin artması ve ilave teknolojiler nedeniyle üretim kayıplarının azaltılması ve rasyonel kullanımı, endüstrilerin geliştirilmesi için yeni fırsatlar, rutin, tekrarlayan ve tehlikeli görevleri insanlardan makinelere ve robotlara taşımak, geleceğin endüstrilerini yaratmak için insan kaynaklarını, makineleri ve algoritmaları birleştirmek gibi özellikle insan kaynaklarının geliştirilmesi için bir dizi yeni fırsatlar yaratmaktadır (Chulanova, 2019: 13). İ 4.0 kavramı ise, "yetenek yönetimi süreçlerinin dijital platformlar aracılığı ile yürütüldüğü, operasyonel süreçlerin kısaldığı, mobilitenin hız kazandığı, çalışanlara hayallerini gerçekleştirebilecekleri bir gelişim ortamı sunan yenilikçi bir yaklaşım" olarak tanımlanmaktadır. Yeni nesil İK’nın kurumların dijital dönüşümüne liderlik etmesi beklenmektedir (Asiltürk, 2018: 537).

Dijital dönüşüm, iK işlevlerinin kuruluşlarda gerçekleştirdiği geleneksel yöntemleri sorgulamaktadır (Fenech, Baguant ve Ivanov, 2019: 168). Dijital dönüşüm konusundaki görüşün stratejik bir konu olduğu düşünüldüğünde, dijital olarak düşünmek artık tek bir departmana ayrılmamıştır. Öncelikle İnsan Kaynakları Yönetimi'ne (HRM) dijital dönüşümün gücünden faydalanmada önemli bir rol oynama şansı vermektedir (Som, 2019: 2).

Akıllı, mobil bağlantılı dijital dünya, şirketleri tamamen yeni bir teknoloji altyapısı oluşturmaya ve desteklemeye itiyor. Bu "teknoloji ağı", ürün ve hizmetler, müşteri deneyimi, operasyonlar ve işgücü gibi kritik dijital boyutlarda işletmeleri güçlendiren öncü Sosyal Medya, Mobilite, Analitik, Bulut ve Nesnelerin İnterneti (SMACI) teknolojilerinin etkileşimidir (Betchoo, 2016: 2).

Teknolojinin kullanımı mevcut İK işlevlerini kolaylaştırır ancak dijitalleşme IKKY'yi sadece günlük idari işleri kolaylaştırmaktan daha fazla etkiler. Dijitalleşmenin, İK planlama; işe alım ve seçim; performans yönetimi; ödül yönetimi; sağık ve güvenlik; çalışan ilişkileri; iş tasarımı gibi işlevlere etkileri vardır. Bununla birlikte, iK işlevine yeni görevler de eklemiştir. Dijitalleşme ikY'ye organizasyondaki insan sermayesinin dijital çağın stratejik ihtiyaçları ile uyumlu bir sermaye olmasını sağlama sorumluluğu da eklemiştir (Fenech, Baguant ve Ivanov, 2019: 168).

Dijitalleşme sadece endüstriyel üretim ve çalışma sürecini değiştirmemekte; doğal kaynaklar sektöründen hizmetler sektörüne kadar ekonominin bütün sektörlerini de etkisi altına almaktadır. Dolayısıyla, bütün iş ve mesleklerde çalışanlar dijitalleşme nedeniyle değişime maruz kalmaktadır. Bu değişimin bütün iş ve mesleklerin tüm doğasını, iş süreçlerini ve görev yapılarını, beceri ve yetkinlik düzeylerini etkileyeceği beklenmektedir (Seçer, 2017: 763).

Birçok endüstride, işletmelerin çalışanlardan talep ettiği beceri ve yeterliliklerde önemli değişiklikler olmuştur. Ayrıca, işgücü miktarına olan talep, insanlara olan ihtiyacı ortadan kaldıran otomasyon ve yapay zeka gibi teknolojilerin yaygınlaşmasıyla da değişmektedir. Bu süreçte en çok tartışılan konulardan biri, Dijital Teknolojilerin ekonomideki yayılmasının istihdam veya işsizlik üzerindeki etkisidir (Demir, 2019: 4).

Sanal dünyada dijitalleşme akıllı operasyonlar şeklinde bulunur. Yenilikçi algoritmalar ve veri analizi ile veriler yeni bir kaynağa dönüştürülür. Bu, piyasa konumunu belirleyen yeni geçerli güçtür. Aynı zamanda, dijital çağ çalışanların kişisel ve mesleki yaşamlarını üstlenmelerini sağlar. Büyük veri ík dilinde giderek yaygınlaşan bir kavramdır ve gelecekte iyi yapılandırılmış ve kullanıldığında bu bileşenin işe alım sürecinde bu bilgileri kullanan şirkete artı değer getirebileceği açıktır (Tataru, 2019: 477).

İçinde bulunduğumuz yeni dönemde akıllı fabrikalar, sanal dünya ile fiziksel olanı en iyi biçimde yorumlayıp ikisini müşteri ihtiyaçları doğrultusunda senkronize eden, çok iyi gözlemci, planlamacı ve pro-aktif çalışanlara (Smart Workers) olan ihtiyacı artıracaktır. Bu IK planlaması açısından, sadece işi yapan değil, işi geliştiren çalışanları yetiştirmeyi veya bulmayı zorunlu kılmaktadır (Alçın, 2016: 46-47). Bütün bunlarla birlşkte dijitalleşemin İnsan Kaynaklarına sağladığı bir çok fayda bulunmaktadır, bu faydalardan bazıları şu şekşilde sayılabilir (Göktaş ve Baysal, 2018: 1416):

Işe Alım ve Yetenek Yönetimi: Dijitalleşme sayesinde işletmeler işe alım sürecini etkili ve hızlı bir şekilde yönetebilmektedir. Dijital ortamlar sayesinde aday havuzuna ulaşmak ve nitelikli başvuruları bir arada görmek kolaylaşmaktadır. İnsan kaynakları, adayların özgeçmişlerini daha hızlı ve doğru şekilde kayıt edebilmekte ve gerekli pozisyon için uygun adayı kolayca seçebilmektedir.

Esnek Çalışma Çözümleri ve Çalışan Memnuniyetinin Artması: çalışanlar dijital teknolojiler sayesinde daha esnek çalışabilmekte bu da çalışan memnuniyetini arttırmaktadır.

Bilginin Erişilebilirliği ve Fırsatların Analizi: Şirketler ve çalışanlar için çok sayıda bilgiye aynı anda ulaşmak büyük fırsatlar sunmaktadır. Çünkü farklı kaynaklardan uzun zamanda elde edebilecekleri bilgileri analiz etmeleri ve sonuçlara ulaşmaları gitgide kolaylaşmaktadır.

Zamanın Etkili Kullanımı: Çalışanın özlük işleri, verilmesi gereken eğitimi, performansının değerlendirilmesi gibi işlemler insan kaynakları için yoğun mesailer anlamına gelmektedir. Dijitalleşme sayesinde bu süreçler daha verimli bir şekilde yönetilebilmektedir. 
Şirketlerin dijital iK'da önce strateji belirlemeleri gerekmektedir. Ardından sosyal medya iletişimi, mobil iK servisleri, bulut iK, entegre iK platformları geliyor. İnsan kaynaklarında dijitalleşme için öncelikle odaklanılması gereken noktalardan birisi çalışan kuşakları arasındaki farklılıkları eritecek stratejiler ve uygulamalar geliştirmektir (Aktaş News, 2018: 12). Şirketlerin küresel rekabet avantajı kazanması için artık alışılagelmiş kalıpların dışına çıkarak, robotik kaynaklardan yararlanması ve insan kaynaklarına yeni yetkinlikler kazandırması ile mümkün olabilecektir (Şendoğdu, 2020: 172).

\section{VERI VE YÖNTEM}

Araştırma, nitel araştırma yöntemlerinden içerik analizi yöntemi ile gerçekleştirilmiştir ve araştırmada, amaçı̈ı örnekleme yöntemi kullanılmıştır. Araştırmada, örneklem olarak belirlenen işletme yöneticileri ve insan kaynakları yöneticileri ile yapılan röportajlar, işletme ile ilgili haberler ve ilgili işletmelerin web sitelerinden elde edilen ikincil veriler kullanılmıştır.

Verilerin toplanması amacıyla, "Dijital İnsan Kaynakları Yönetimi”, "Dijital Dönüşüm iK", "Dijital Dönüşüm İnsan Kaynakları Yönetimi", "Dijital İşletme" başlıkları ile aramalar yapılmıştır. Yapılan aramalar neticesinde "Dijital İnsan Kaynakları Uygulamaları" kriterine uyan ve işletme yöneticileri veya İk yöneticileri ile yapılan röportaj ve haberler araştırma kapsamına alınmıştır. Bu sayede 16 (onaltı) işletme araştırmanın örneklemini oluşturmuştur. Araştırma örneklemini oluşturan işletmelerin internet sitelerinden ikinci bir tarama yapılmıştır ve elde edilen bilgiler sınıflandırılmıştır. Son olarak işletmenin isimi ve "Dijital İnsan Kaynakları" ve "Dijital IK" başlıkları ile tekrar bir arama yapılarak bulunan röportaj ve haberler araştırmaya dâhil edilmiştir.

\section{BULGULAR VE TARTIŞMA}

Yapılan araştırma sonucunda; Akbank, Abdi İbrahim Illaç, Borusan Holding, BSH Türkiye, DenizBank, Doğuş Otomotiv, LC Waikiki, Mercedes-Benz Türk, Migros, P\&G Türkiye, PepsiCo Türkiye, SabancıDx, Schneider Electric Türkiye, TAB Gıda, Yaşar Holding ve Yıldız Holding işletmelerinin dijital insan kaynakları uygulamalarına ait veriler elde edilmiştir. Söz konusu işletmelere ait bulgular Tablo 1'de görülmektedir.

\section{Tablo 1: Dijital İnsan Kaynakları Uygulamaları Tablosu}

\begin{tabular}{|c|c|}
\hline Işletme & Dijital İnsan Kaynakları Uygulamaları \\
\hline Akbank $^{1}$ & $\begin{array}{l}\text { - Doğal dil işleme (NLP) tabanlı IK Chatbot “1Bilen” üzerinden çalışanların IK uygulamalarına çok kısa sürede ulaşarak } \\
\text { işlemlerini gerçekleştirebilmesi sağlanıyor, } \\
\text { - KOBI’lerin İnsan Kaynakları Yönetimini “Kolay IK" projesi ile Dijital Dünyaya Aktardı, } \\
\text { - "Kolay IK" projesi ile KOBi’lerin maaş ödemesi, bordro, izin, eğitim, harcama, zimmet, özlük bilgileri gibi birçok konuda } \\
\text { şirket çalışanlarına dair süreçlerini bilgisayar, akıllı telefon ya da tabletlerinden, güvenli bir şekilde yönetebilmeleri } \\
\text { sağlanıyor. }\end{array}$ \\
\hline Abdi İbrahim İlaç² & $\begin{array}{l}\text { - İşe alım süreçleri tamamen dijital olarak yürütülüyor, } \\
\text { - İşe alımlarda ön eleme yapay zekâ tarafından yapılıyor, } \\
\text { - Mavi yaka iş başvuruları internet üzerinden QR kod ya da bir linkle oluşturulan başvuru formu kullanılarak } \\
\text { gerçekleştiriliyor, } \\
\text { - Çalışanlar izin, e-bordro gibi talep ya da dokümanlara mobil uygulama üzerinden ulaşabiliyor, } \\
\text { - Takdir ve ödüllendirme platformunda çalışanlar, puanlarını sistem üzerinden hediye çeklerine dönüştürebiliyor. }\end{array}$ \\
\hline
\end{tabular}

\footnotetext{
${ }^{1}$ www.akbank.com/tr; www.akbanklab.com/tr; www.finans365.com; www.capital.com.tr; www.fintechtime.com/tr; www.bloomberght.com; www.milliyet.com.tr; www.capital.com.tr.

${ }^{2}$ www.abdiibrahim.com.tr; www.hurriyet.com.tr; www.capital.com.tr; www.turkchem.net; www.fintechtime.com/tr; www.bloomberght.com; www.milliyet.com.tr; www.capital.com.tr.
} 


\begin{tabular}{|c|c|}
\hline Borusan Holding ${ }^{3}$ & $\begin{array}{l}\text { - Tüm süreçlerin dijitalde olması hedefleniyor, } \\
\text { - Borusan İnsan Mobil Uygulaması kullanılıyor, } \\
\text { - Borusan'daki tüm İK süreçlerinden çalışanlar, Borusan Insan Mobil Uygulaması ile haberdar olabiliyor. Ödüllü } \\
\text { - yarışmalar, anketler, eğlenceli, öğretici video ve içerikler bu uygulamada sunuluyor, } \\
\text { - Mobil uygulama desteği ile oryantasyon eğitimi veriliyor, } \\
\text { - Mobil uygulama desteği ile çalışanlara online geri bildirim veriliyor, } \\
\text { - Borusan İnsan Dashboard ile veriye dayalı analizler, raporlamalar ve executive dashboard’ların yer aldığı mobil uyumlu } \\
\text { insan kaynakları analitik uygulama ile tüm raporlara ve analizlere tek bir sistem üzerinden hızlı erişim sağlanıyor, } \\
\text { - Borusan İnsan Chatbot, gelen soruların yapay zekâ aracılığıyla yanıtlanabildiği chatbot uygulamasıdır. Bu uygulama ile } \\
\text { İK süreçleri ile ilgili } 4 \text { binden fazla soruya anında yanıt vererek hem ik ekiplerinin hem de çalışanların hayatı } \\
\text { - kolaylaştırılıyor, } \\
\text { - Tüm insan kaynakları süreçlerinin yöneticiler, çalışanlar ve İk tarafından yürütülebileceği mobil uyumlu bir dijital } \\
\text { önceliklendirmek ve en uygun yetenekleri Borusan'a çekmek ana hedefler arsında. }\end{array}$ \\
\hline BSH Türkiye ${ }^{4}$ & $\begin{array}{l}\text { - Eskiden kadro hesaplamaları ve raporlamalar manuel veri girişi ile yapıldığı için dikkate değer bir iş gücü ve zaman } \\
\text { kaybedilirken bu süreçlerin dijital platformlara taşınması ile çok daha kısa zamanda ve daha az iş gücüyle hata } \\
\text { minimuma indirilerek işlemler yapılıyor, } \\
\text { - Dijital işlemler sayesinde, çalışanların ve potansiyel yeteneklerin ihtiyaçları doğrultusunda katma değer yaratılabilecek } \\
\text { alanlara odaklanılıyor. }\end{array}$ \\
\hline DenizBank $^{5}$ & $\begin{array}{l}\text { - İnsan Kaynakları süreçleri dijital platforma taşınmış durumda, } \\
\text { - Yöneticiler tabletleri üzerinden tüm uygulamalara erişip } 7 / 24 \text { işlemlerini sonuçlandırabiliyorlar, } \\
\text { - İşe alımlarda adaylarla ve iç ilan başvurusunda, atama izin gibi her işlem elektronik akışlarla yürütülyor, } \\
\text { - İşe alım süreçlerinde video ve online mülakatlar yapılıyor, } \\
\text { - Performans yönetimi, terfi, tayin, çıkış vb. kariyer yönetimindeki iş süreçleri tamamen online ortamda ilerliyor, } \\
\text { - İleride işe alımların robotlar aracılığıyla yapılması planlanıyor, } \\
\text { - Y Yılda bir kez yapılan performans ve çalışan bağlıık analizleri ve değerlendirmeleri yerine mobil çözümlerle şirketin anlık } \\
\text { - nabzı ölçülebiliyor, } \\
\text { - 'Dhatbot, İnsan Kaynakları Facebook sayfasında kullanıcıların sorularına } 7 \text { gün } 24 \text { saat geri dönüş sağlıyor, } \\
\text { - 'Deniz'in İncisi', tamamen dijital ve kişiye özel işe alım deneyimi sunan üniversite öğrencilerine yönelik staj } \\
\text { - 'Drogramıdır, } \\
\text { - Çalışanlar ile sürekli ve hızlı iletişim olanağı sağlayan ‘DenizBank Whatsapp' uygulaması bulunmaktadır, } \\
\text { - Skype platformu üzerinden 'Sanal Kariyer Fuarı' yapılmaktadır. }\end{array}$ \\
\hline
\end{tabular}

${ }^{3}$ www.borusan.com/tr; www.magg4.com; www.hrdergi.com; www.fintechtime.com/tr; www.bloomberght.com; www.milliyet.com.tr; www.capital.com.tr.

${ }^{4}$ www.bsh-group.com; www.hrdergi.com; www.blog.bsh-group.com.tr; www.fintechtime.com/tr; www.bloomberght.com; www.milliyet.com.tr; www.capital.com.tr.

${ }^{5}$ www.denizbank.com; www.ikmagazin.com; www.hrdergi.com; www.haberler.com. 
- Eskiden İK departmanında manuel takip edilen ve operasyonel olarak işlem yükü yaratan birçok süreç artık dijital platformlarda yürütüyor,

- Potansiyel Çalışan ve Yedekleme Süreci modülü olan D-İnsan 4.0 performans sisteminde geliştirilmiştir. Bu modül ile birlikte yetenek yönetimi süreçleri ve altyapısı dijitalleştirilerek, sistemsel anlamda hem kurumsal hafıza yaratılmış hem de eğitim ve gelişim faaliyetlerinde faydalanılacak bir modül tasarlanmıştır,

- Yeni işe başlayan çalışanların Şirket'i daha iyi tanımaları ve adaptasyonlarını daha hızlı sağlamak için oyunlaştırma temelli Mobil Oryantasyon Programı kullanılmasına ve aday işe giriş sınav ve kişilik envanteri süreçlerinin online sistem üzerinden gerçekleştirilmesine başlanmıştır,

Doğuş Otomotiv 6

- Insan Kaynaklarının her alanında dijitalleşmeye gidilmiştir. İşe alım ve yerleştirme, eğitim ve gelişim, çalışan hakları ve bilgilendirme, süreç yönetimi, idari ve teknik işler gibi birçok alanda dijital projeler geliştirilmeye devam edilmektedir,

- Insan Kaynakları raporlamalarının yapıldığı ve şirket yönetimine de açık olan Raporlama araçlarında iyileştirmeler ve yeni raporlar tasarlanarak, dashboardlar oluşturulmaya devam edilmektedir,

- D-İnsan 4.0 performans yönetim sistemindeki geliştirme ile yedek parça lojistik depoda görev alan mavi yaka çalışanların performans değerlendirmeleri aylık olarak ölçümlenen kriterler ile yıllık performanslarını oluşturulacak şekilde D-insan 4.0 sistemine aktarılmıştır.

Doğru kişiyi işe almak için süreçler dijitalleştirilmiş durumda,

- IK metrikleri dijitalleştirilerek dashboardlara taşınmış durumda,

- Çalışanlar önemli özlük bilgilerini ve onay süreçlerini mobil uygulamalardan takip edebiliyorlar.

- Biziz App adında bir mobil uygulama geliştirilmiş durumda,

- Biziz App uygulaması ile çalışanlar şirketten en güncel haberlere ve çalışanlara özel indirim oranlarına hızlıca ulaşabiliyorlar, aynı zamanda günlük yemek menüsü ve servis saatleri ile ilgili güncel bilgi alabiliyorlar,

Mercedes-Benz Türk $^{8}$

- Bunun yanında, şirket içi iletişim platformu üzerinden çalışanlar tüm dünyadaki şirket çalışanlarıyla iletişim kurup ilgi alanlarına yönelik gruplarda bilgi ve deneyimlerini paylaşabiliyorlar.

- Eskiden mağazalardan alınan iş başvuruları, QR kodla adaylar için pratik hale getirilmiş durumda,

- Bununla beraber çalışanların süreçlerini hızlandırmak için 2016 yılında ík Mobil uygulaması hayata geçirildi,

- IK Mobil uygulaması ile ayrıca yöneticiler çalışanlarına özel tüm onay işlemlerine ve departmanlara özel ik raporlamalarına erişebiliyorlar.

- VR içerikli kampüs aktiviteleri gerçekleştiriliyor,

- Dijital işe alım süreci gerçekleştiriliyor,

- Dijital eğitim programları kullanılıyor,

- Dijital ödüllendirme sistemleri bulunuyor,

- Dijital kariyer ve performans yönetim sistemi uygulanıyor,

- IK süreçleri dijital araçlarla gerçekleştiriliyor.

- Değerlendirme merkezi uygulaması dijitalleştirilmiş durumda,

- IK içinde shared service (iK Çözüm Merkezi) yapısı kurulmuş durumda,

- IK üzerinden gelen tüm sorular dijital platformdan alınarak çalışanların ilgili cevaplara ulaşması sağlanıyor ve bunlar takip edilerek raporlanıyor.

${ }^{6}$ www.dogusotomotiv.com.tr; www.odd.org.tr; www.lojiyol.com; www.hurriyet.com.tr; www.fintechtime.com/tr; www.bloomberght.com; www.milliyet.com.tr; www.capital.com.tr.

${ }^{7}$ www.lcwaikiki.com/tr-TR/TR; www.fintechtime.com/tr; www.bloomberght.com; www.milliyet.com.tr; www.capital.com.tr.

${ }^{8}$ www.mercedes-benz.com.tr; www.hurriyet.com.tr; www.fintechtime.com/tr; www.bloomberght.com; www.milliyet.com.tr; www.capital.com.tr.

${ }^{9}$ www.migros.com.tr; www.aa.com.tr/tr; www.hrdergi.com; www.fintechtime.com/tr; www.bloomberght.com; www.milliyet.com.tr; www.capital.com.tr.

${ }^{10}$ www.pg.com.tr/; www.hurriyet.com.tr; www.hrdergi.com; www.fintechtime.com/tr; www.bloomberght.com; www.milliyet.com.tr; www.capital.com.tr.

${ }^{11}$ www.pepsico.com.tr; www.hurriyet.com.tr; www.kariyer.net; www.peryon.org.tr; www.fintechtime.com/tr; www.bloomberght.com; www.milliyet.com.tr; www.capital.com.tr. 
SabancIDx ${ }^{12}$

Schneider Electric Türkiye $^{13}$

TAB GIda ${ }^{14}$
- SabancıDx, HR-Web ile dijital insan kaynakları ve bordrolama çözümü sağlanıyor ve tüm İK süreçleri bu ürün aracılığıyla yürütülüyor,

- HR Web, robotik süreç otomasyonunu, işe alım-işten çıkış, eğitim ve sağlık kayıtları düzenleme, SGK teşvik hesaplamaları gibi süreçlerde kullanılıyor,

- Mobil destekli raporlama gerçekleştiriliyor,

- Self servis özelliği ile HR-Web, çalışanlara, kendi işlemlerini kendilerinin yapabilmesi avantajını sunuyor. Bu sayede, çalışanların iş süreçlerini benimsemeleri sağlanıyor ve İnsan Kaynakları Departmanı́nın üzerindeki iş yoğunluğu azaltılıyor,

- 2018 yıında İnsan Kaynakları süreçlerinin dijitalizasyonu ve İK Analitiği uygulamalarının hayata geçirilmesi amacı ile "HR-Next" projesi başlatılmıştır,

- Proje kapsamında ilk adımda, Topluluk şirketlerindeki tüm çalışanlara ait ik verilerinin ortak bir veri tabanına aktarılması sağlanarak IKKolay Veri Tabanı hayata geçirilmiştir. 2019 senesinde de "HR-Next" projesinin 4 ana proje modülü olan Performans Yönetimi, Sabancı Sosyal Ağ, Veri Analitiği, Organizasyonel Başarı Planı projeleri yürütülmüştür.

- Yapay zekâ özellikli bir teknoloji olan Açık Yetenek Pazarı platformu ile kurum içinde işlerin yanı sıra projeler ve mentörlük fırsatları da paylaşılıyor,

- Açık Yetenek Pazarı platformu ile çalışanlar kendi yeteneklerini kendileri değerlendiriyor ve amaçlarını ve hedeflerini paylaşıyor. Bir beceri ağı olarak çalışanların yeteneklerini doğrudan ilgili yöneticilere sunmalarına olanak sağlıyor. Mentörler bularak veya yeteneklerini projeler aracılığıyla başka yöneticilerin kullanımına sunarak kendilerini geliştirmeleri mümkün oluyor. Bu konuda IK'ya veya mevcut yöneticilerine bağımlı olmuyorlar. Yapay zeka teknolojisi aynı zamanda standart değerlendirmelerin dışında kalan ilginç fırsatları çalışanlara sunuyor,

- Çalışanlar hareket halindeyken dahi gündelik küçük ölçekli dijital öğrenmeyi kolaylaştırmak amacıyla mobil öğrenme platformu hayata geçirilmiş durumda. Bu platform kurum dışı dijital öğrenme içeriğ̈̌nden ve Schneider Electric'in kurum içi özel öğrenme içeriğinden birlikte faydalanıyor,

- Dijital öğrenme yöntemleri, 'Dijital Pasaport' olarak adlandırılan yöntem ve diğer dijital konular kapsamında tüm çalışanların kullanımına sunuluyor. Böylece Schneider Electric çalışanları 'Dijital Vatandaşlar' haline geliyor. Bu yaklaşım aracılığıyla çalışanlar, bilgi ve becerilerini güncellemeye, yenilemeye ve dijital trendleri yakalamaya teşvik ediliyorlar,

- Çalışanların dijital alandaki becerilerini artırmaya yönelik bu çabaların yanı sıra özel işler için belirli teknik konularda dijital öğrenme olanakları ve dünyadaki en önemli 1000 lidere özel bir mobil platform sağlanıyor. Bu mobil yaklaşım yeni trendleri öğrenme, bildiklerini tazeleme ve liderlerin hayat boyu öğrenerek hep güncel kalmasını sağlama yöntemlerini dönüştürüyor,

- Tüm İ veri tabanını bir platform üzerine taşımak, verinin yöneticiler tarafından da görüntülenip yönetilebileceği bir platforma dönüştürmek konusunda önemli çalışmalar yapılmış durumda,

- Performans değerlendirme süreci ve ücret artış işlemleri bu platform üzerinden tamamlanmaya başlandı. Bu sayede yüksek performans kültürü inisiyatifi doğrultusunda yöneticilerin ekip yönetimi çerçevesinde sorumluluk alanları genişletilmiş durumda. Yalınlaşma ve dijitalleşme üzerine atılan bu global adım ile birlikte, iş birimleri ve İ'nın yakın temas halinde olması sağlanmış durumdadır,

- Hedefler, gelişim planları ve yetenek yönetimi de bu platform üzerinden yönetiliyor; çalışanlar kendilerine ait bilgileri, güncellemeleri de dijital olarak yönetebiliyor,

- Dijital platformlarda verinin yönetilmesi şirketi global anlamda bulunabilir, görüntülenebilir ve açık pozisyonlar için erişilebilir kılıyor ki, asıl amaç da zaten global roller, projelerde yer almak, isteyenleri bu platformda değerlendirebilmek. Böylece hem İ, hem de çalışanlar kariyer basamaklarını buradan yönetebiliyor,

- Dijitalleşme kapsamında işe alımlarda video mülakat aracı kullanıyor. Bu sistem sayesinde hem adaylar, hem de şirket, zaman tasarrufu sağlayarak süreci hızlandırabiliyor. Buna ek olarak stajyer gibi toplu alımlarda da yine aynı kanal üzerinden pek çok öğrenciye ulaşıp kısa zamanda etkin değerlendirmeler yapabiliyor,

- Dijitale geçen süreçler sayesinde İK departmanı, şirket içindeki diğer iş birimlerine daha fazla zaman ayırabiliyor.

- Dijital platformların sağladığı kolaylıklar ile İK daha kıymetli uygulamalar ile ilgilenebiliyor,

- Eğitim tekniklerinde dijitalleşme ve online eğitimler kullanılıyor.

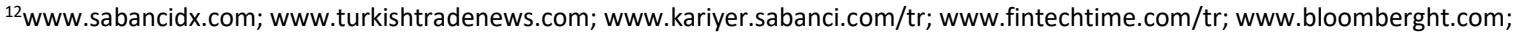
www.milliyet.com.tr; www.capital.com.tr.

${ }^{13}$ www.se.com/tr/tr; www.hrdergi.com/; www.hurriyet.com.tr; www.fintechtime.com/tr; www.bloomberght.com; www.milliyet.com.tr; www.capital.com.tr.

${ }^{14}$ www.tabgida.com.tr; www.fintechtime.com/tr; www.bloomberght.com; www.milliyet.com.tr; www.capital.com.tr. 


\begin{tabular}{|c|c|}
\hline Yaşar Holding ${ }^{15}$ & $\begin{array}{l}\text { - Kâğıtsız dijital ortam kullanılıyor, } \\
\text { - SAP'yle entegre olan İK sistemi mobil uygulamaya da taşınıyor, } \\
\text { - İşe alımlar, aday havuzu işlemleri, iş ve staj başvuruları, Yaşar Kariyer Platformu üzerinden gerçekleştiriliyor, } \\
\text { - Çeşitli istihdam süreçleri dijital platform aracılığıyla yürütülüyor, } \\
\text { - Yönetim kademeleri süreçlerini desteklemek için SAP bazlı İK yönetim raporları oluşturuluyor. }\end{array}$ \\
\hline Yıldız Holding ${ }^{16}$ & $\begin{array}{l}\text { - Paperless HR adında projesi başlatıldı ve bu proje ile 50'den fazla süreçte formlar dijital ortama taşınıyor ve } \\
\text { sürdürülebilirlik politikası çerçevesinde ofislerdeki kâğıt kullanımı en aza indiriliyor, } \\
\text { - İK’nın bordro süreçlerinin önemli bir kısmı robotik süreç otomasyonu (RPA) teknolojisiyle yapılmaya maya başlandı, } \\
\text { - İşe alımlarda adayların performansının ve kurum kültürüne uyumunun tahmin edebileceği bir yapay zekâ üzerinde } \\
\text { çalışılıyor. }\end{array}$ \\
\hline
\end{tabular}

Akbank; bu işletmede, doğal dil işleme (NLP) tabanlı ík Chatbot "1Bilen" üzerinden çalışanların İK uygulamalarına çok kısa sürede ulaşarak işlemlerini gerçekleştirebilmesi sağlanmaktadır. Akbank, KOBi'lerin İnsan Kaynakları Yönetimini "Kolay iK" projesi ile Dijital Dünyaya Aktarmıştır ve "Kolay IK" projesi ile KOBi’lerin maaş ödemesi, bordro, izin, eğitim, harcama, zimmet, özlük bilgileri gibi birçok konuda şirket çalışanlarına dair süreçlerini bilgisayar, akıllı telefon ya da tabletlerinden, güvenli bir şekilde yönetebilmeleri sağlanmaktadır.

Abdi Ibrahim Ilaç; bu işletmede, İşe alım süreçleri tamamen dijital olarak yürütülmektedir. İşe alımlarda ön eleme yapay zekâ tarafından yapılmakta, mavi yaka iş başvuruları internet üzerinden QR kod ya da bir linkle oluşturulan başvuru formu kullanılarak gerçekleştirilmektedir. Bunun yanında, çalışanlar izin, e-bordro gibi talep ya da dokümanlara mobil uygulama üzerinden ulaşabilmekte, takdir ve ödüllendirme platformunda çalışanlar, puanlarını sistem üzerinden hediye çeklerine dönüştürebilmektedirler.

Borusan Holding; bu işletmede, tüm iK süreçlerinin dijitalde olması hedeflenmekteir. Borusan İnsan Mobil Uygulaması kullanılmakta, çalışanlar Borusan'daki tüm İK süreçlerinden, Borusan İnsan Mobil Uygulaması ile haberdar olabilmektedirler. Ayrıca ödüllü yarışmalar, anketler, eğlenceli, öğretici video ve içerikler bu uygulama ile sunulmaktadır. Çalışanlara oryantasyon eğitimleri ve online geri bildirimler mobil uygulama desteği ile verilmektedir. Borusan İnsan Dashboard ile veriye dayalı analizler, raporlamalar ve executive dashboard'ların yer aldığı mobil uyumlu insan kaynakları analitik uygulama ile tüm raporlara ve analizlere tek bir sistem üzerinden hızlı erişim sağlanmaktadır. Borusan İnsan Chatbot, gelen soruların yapay zekâ aracılı̆ıyla yanıtlanabildiği chatbot uygulaması olarak karşımıza çıkmaktadır. Bu uygulama ile İK süreçleri ile ilgili 4 binden fazla soruya anında yanıt verilerek hem İK ekiplerinin hem de çalışanların iş yaşamı kolaylaştırılmaktadır. Tüm insan kaynakları süreçlerinin yöneticiler, çalışanlar ve İK tarafından yürütülebileceği mobil uyumlu bir dijital platform hayata geçirilmiştir. Borusan Holding'de, İşe alımlarda, Al (yapay zekâ), Machine Learning (Makine Öğrenmesi) gibi teknolojiler kulanılarak aday havuzunu dijital olarak önceliklendirmek ve en uygun yetenekleri Borusan'a çekmek ana hedefler arsında yer almaktadır.

BSH Türkiye; bu işletmede, eskiden kadro hesaplamaları ve raporlamalar manuel veri girişi ile yapıldığı için dikkate değer bir iş gücü ve zaman kaybı yaşanırken bu süreçlerin dijital platformlara taşınması ile çok daha kısa zamanda ve daha az iş gücüyle hata minimuma indirilerek işlemler yapılmaktadır. Ayrıca dijital işlemler sayesinde, çalışanların ve potansiyel yeteneklerin ihtiyaçları doğrultusunda katma değer yaratılabilecek alanlara odaklanılmaktadır.

DenizBank; bu işletmede Insan Kaynakları süreçlerinin tamamı dijital platforma taşınmış durumdadır. Yöneticiler tabletleri üzerinden tüm uygulamalara erişip $7 / 24$ işlemlerini sonuçlandırabilmektedirler. Bunun yanında işe alımlarda adaylarla ve iç ilan başvurusunda, atama, izin gibi her işlem elektronik akışlarla yürütülmektedir. Işe alım süreçlerinde video ve online mülakatlar yapılmaktadır. Ayrıca, performans yönetimi, terfi, tayin, çıkış vb. kariyer yönetimindeki iş süreçleri tamamen online ortamda yürütülmektedir. Gelecekte işe alımların robotlar aracılığıyla yapılması planlanmaktadır. Yılda bir kez yapılan performans ve çalışan bağlılık analizleri ve değerlendirmeleri yerine mobil çözümlerle şirketin anlık nabzı ölçülebilmekedir. Chatbot, İnsan Kaynakları Facebook sayfasında, kullanıcıların sorularına 7 gün 24 saat geri dönüş sağlamaktadır. 'DenizAşırı' DenizBank'ın Online staj programıdır, 'Deniz'in İncisi', tamamen dijital ve kişiye özel işe alım deneyimi sunan üniversite öğrencilerine yönelik bir staj programıdır, 'Denizde' uygulaması ise çalışanların ödüller kazanabildiği eğitim ve özel fırsatlara kolayca erişebildikleri şirket içi mobil uygulamasıdır. Çalışanlar ile sürekli ve hızı iletişim olanağı sağlayan 'DenizBank Whatsapp uygulaması bulunmaktadır. Ayrıca, bu işletmede Skype platformu üzerinden 'Sanal Kariyer Fuarı' yapılmaktadır.

\footnotetext{
${ }^{15}$ www.yasar.com.tr; www.fintechtime.com/tr; www.bloomberght.com; www.milliyet.com.tr; www.capital.com.tr.

${ }^{16}$ www.yildizholding.com.tr; www.fintechtime.com/tr; www.bloomberght.com; www.milliyet.com.tr; www.capital.com.tr.
} 
Doğuş Otomotiv; bu işletmede, eskiden ík departmanında manuel takip edilen ve operasyonel olarak işlem yükü yaratan birçok süreç artık dijital platformlarda yürütülmektedir. Potansiyel Çalışan ve Yedekleme Süreci modülü olan D-İnsan 4.0 performans sistemi geliştirilmiştir. Bu modül ile birlikte yetenek yönetimi süreçleri ve altyapısı dijitalleştirilerek, sistemsel anlamda hem kurumsal hafıza yaratılmış hem de eğitim ve gelişim faaliyetlerinde faydalanılacak bir modül tasarlanmıştır. Yeni işe başlayan çalışanların Şirket'i daha iyi tanımaları ve adaptasyonlarını daha hızlı sağlamak için oyunlaştırma temelli Mobil Oryantasyon Programı kullanılmasına ve aday işe giriş sınav ve kişilik envanteri süreçlerinin online sistem üzerinden gerçekleştirilmesine başlanmıştır. İnsan Kaynaklarının her alanında dijitalleşmeye gidilmiştir. İşe alım ve yerleştirme, eğitim ve gelişim, çalışan hakları ve bilgilendirme, süreç yönetimi, idari ve teknik işler gibi birçok alanda dijital projeler geliştirilmeye devam edilmektedir. İnsan Kaynakları raporlamalarının yapıldığı ve şirket yönetimine de açık olan raporlama araçlarında iyileştirmeler ve yeni raporlar tasarlanarak, dashboardlar oluşturulmaya devam edilmektedir. D-İnsan 4.0 performans yönetim sistemindeki geliştirme ile yedek parça lojistik depoda görev alan mavi yaka çalışanların performans değerlendirmeleri aylık olarak ölçümlenen kriterler ile yıllık performanslarını oluşturulacak şekilde D-i̇nsan 4.0 sistemine aktarılmıştır.

LC Waikiki; Doğru kişiyi işe almak için süreçler dijitalleştirilmiş durumdadır. İK metrikleri dijitalleştirilerek dashboardlara taşınmış durumdadır. Ayrıca, çalışanlar önemli özlük bilgilerini ve onay süreçlerini mobil uygulamalardan takip edebilimektedirler.

Mercedes-Benz Türk; Biziz App adında bir mobil uygulama geliştirilmiş durumdadır. Biziz App uygulaması ile çalışanlar şirketten en güncel haberlere ve çalışanlara özel indirim oranlarına hızlıca ulaşabilmektedirler. Aynı zamanda günlük yemek menüsü ve servis saatleri ile ilgili güncel bilgiyi bu uygulamadan öğrenebilmektedirler. Bunun yanında, şirket içi iletişim platformu üzerinden çalışanlar tüm dünyadaki şirket çalışanlarıyla iletişim kurup ilgi alanlarına yönelik gruplarda bilgi ve deneyimlerini paylaşabilmektedirler.

Migros; eskiden mağazalardan alınan iş başvuruları, QR kodla adaylar için pratik hale getirilmiş durumdadır. Bununla beraber çalışanların süreçlerini hızlandırmak için 2016 yılında IK Mobil uygulaması hayata geçirilmiştir. İ Mobil uygulaması ile ayrıca yöneticiler çalışanlarına özel tüm onay işlemlerine ve departmanlara özel İK raporlamalarına erişebilmektedirler.

P\&G Türkiye; bu işletmede, VR içerikli kampüs aktiviteleri ve dijital işe alım süreci gerçekleştirilmektedir. Ayrıca, dijital eğitim programları kullanılmakta, dijital ödüllendirme sistemleri bulunmakta, dijital kariyer ve performans yönetim sistemi uygulanmakta, íK süreçleri dijital araçlarla gerçekleştirilmektedir.

PepsiCo Türkiye; bu işletmede, Değerlendirme Merkezi Uygulaması dijitalleştirilmiş durumdadır. Bunun yanında, iK içinde shared service (İK Çözüm Merkezi) yapısı kurulmuştur. Ayrıca, İK üzerinden gelen tüm sorular dijital platformdan alınarak çalışanların ilgili cevaplara ulaşması sağlanmakta ve bunlar takip edilerek raporlanmaktadır.

SabancıDx; bu işletmede HR-Web ile dijital insan kaynakları ve bordrolama çözümü sağlanmakta ve tüm ík süreçleri bu ürün aracılığıyla yürütülmektedir. HR Web, robotik süreç otomasyonunu, işe alım-işten çıkış, eğitim ve sağılk kayıtları düzenleme, SGK teşvik hesaplamaları gibi süreçlerde kullanılmaktadır. Mobil destekli raporlama gerçekleştirilmektedir. Self servis özelliği ile HRWeb, çalışanlara, kendi işlemlerini kendilerinin yapabilmesi avantajını sunmaktadır. Bu sayede, çalışanların iş süreçlerini benimsemeleri sağlanmakta ve İnsan Kaynakları Departmanı’nın üzerindeki iş yoğunluğu azaltılmaktadır. 2018 yılında İnsan Kaynakları süreçlerinin dijitalizasyonu ve İK Analitiği uygulamalarının hayata geçirilmesi amacı ile "HR-Next" projesi başlatılmıştır. Proje kapsamında ilk adımda, Topluluk şirketlerindeki tüm çalışanlara ait í verilerinin ortak bir veri tabanına aktarılması sağlanarak iKolay Veri Tabanı hayata geçirilmiştir. 2019 senesinde de "HR-Next" projesinin 4 ana proje modülü olan Performans Yönetimi, Sabancı Sosyal Ağ, Veri Analitiği, Organizasyonel Başarı Planı projeleri yürütülmüştür.

Schneider Electric Türkiye; bu işletmede, yapay zekâ özellikli bir teknoloji olan Açık Yetenek Pazarı platformu ile kurum içinde işlerin yanı sıra projeler ve mentörlük fırsatları da paylaşılmaktadır. Bu platform ile çalışanlar kendi yeteneklerini kendileri değerlendiriyor ve amaçlarını ve hedeflerini paylaşıyor ve bir beceri ağı olarak çalışanların yeteneklerini doğrudan ilgili yöneticilere sunmalarına olanak sağlıyor. Bu sayede, mentörler bularak veya yeteneklerini projeler aracılı̆̆ıla başka yöneticilerin kullanımına sunarak kendilerini geliştirmeleri mümkün oluyor. Bu konuda İK'ya veya mevcut yöneticilerine bağımlı olmuyorlar. Yapay zeka teknolojisi aynı zamanda standart değerlendirmelerin dışında kalan ilginç fırsatları çalışanlara sunumaktadır.

Çalışanlar hareket halindeyken dahi gündelik küçük ölçekli dijital öğrenmeyi kolaylaştırmak amacıyla mobil öğrenme platformu hayata geçirilmiş durumdadır. Bu platform kurum dışı dijital öğrenme içeriğinden ve Schneider Electric'in kurum içi özel öğrenme içeriğinden birlikte faydalanmaktadır. Dijital öğrenme yöntemleri, 'Dijital Pasaport' olarak adlandırılan yöntem ve diğer dijital konular kapsamında tüm çalışanların kullanımına sunulmaktadır. Böylece Schneider Electric çalışanları 'Dijital Vatandaşlar' haline gelmektedirler. Bu yaklaşım aracılı̆̆ıyla çalışanlar, bilgi ve becerilerini güncellemeye, yenilemeye ve dijital trendleri yakalamaya teşvik ediliyorlar. Çalışanların dijital alandaki becerilerini artırmaya yönelik bu çabaların yanı sıra özel işler için belirli teknik 
konularda dijital öğrenme olanakları ve dünyadaki en önemli 1000 lidere özel bir mobil platform sağlanmaktadır. Bu mobil yaklaşım yeni trendleri öğrenme, bildiklerini tazeleme ve liderlerin hayat boyu öğrenerek hep güncel kalmasını sağlama yöntemlerini dönüştürmektedir. Tüm İK veri tabanını bir platform üzerine taşımak ve verinin yöneticiler tarafından da görüntülenip yönetilebileceği bir platforma dönüştürmek konusunda önemli çalışmalar yapılmış durumdadır.

Performans değerlendirme süreci ve ücret artış işlemleri bu platform üzerinden tamamlanmaya başlanmıştır. Bu sayede yüksek performans kültürü inisiyatifi doğrultusunda yöneticilerin ekip yönetimi çerçevesinde sorumluluk alanları genişletilmiş durumdadır. Yalınlaşma ve dijitalleşme üzerine atılan bu global adım ile birlikte, iş birimleri ve İK'nın yakın temas halinde olması sağlanmış durumdadır. Hedefler, gelişim planları ve yetenek yönetimi de bu platform üzerinden yönetilmektedir. Çalışanlar kendilerine ait bilgileri, güncellemeleri de dijital olarak yönetebilmektedirler.

Dijital platformlarda verinin yönetilmesi, şirketi global anlamda bulunabilir, görüntülenebilir ve açık pozisyonlar için erişilebilir kılıyor ki, asıl amaç da zaten global roller, projelerde yer almak isteyenleri bu platformda değerlendirebilmektir. Böylece hem ik, hem de çalışanlar kariyer basamaklarını buradan yönetebiliyorlar. Dijitalleşme kapsamında işe alımlarda video mülakat aracı kullanılmaktadır. Bu sistem sayesinde hem adaylar, hem de şirket, zaman tasarrufu sağlayarak süreci hızlandırabilmektedirler. Buna ek olarak stajyer gibi toplu alımlarda da yine aynı kanal üzerinden pek çok öğrenciye ulaşıp kısa zamanda etkin değerlendirmeler yapabilmektedir. Dijitale geçen süreçler sayesinde íK departmanı, şirket içindeki diğer iş birimlerine daha fazla zaman ayırabilmektedir.

TAB Gıda; bu işletmede dijital platformların sağladığı kolaylıklar sayesinde ík daha kıymetli uygulamalar ile ilgilenebilmektedir. Ayrıca, eğitim tekniklerinde dijitalleşme ve online eğitimler kullanılmaktadır.

Yaşar Holding; bu işletmede Kâğıtsız dijital ortam kullanılmaktadır, SAP'yle entegre olan í sistemi mobil uygulamaya da taşınmaktadır, işe alımlar, aday havuzu işlemleri, iş ve staj başvuruları, Yaşar Kariyer Platformu üzerinden gerçekleştirilmektedir, çeşitli istihdam süreçleri dijital platform aracılığıyla yürütülmektedir, yönetim kademeleri süreçlerini desteklemek için SAP bazlı íK yönetim raporları oluşturulmaktadır.

Yıldız Holding; bu işletmede, Paperless HR projesi başlatılmıştır ve bu proje ile 50'den fazla süreçte formlar dijital ortama taşınmaktadır ve sürdürülebilirlik politikası çerçevesinde ofislerdeki kâğıt kullanımı en aza indirilmektedir. ík'nın bordro süreçlerinin önemli bir kısmı robotik süreç otomasyonu (RPA) teknolojisiyle yapılmaya başlanmıştır. İşe alımlarda adayların performansının ve kurum kültürüne uyumunun tahmin edebileceği bir yapay zekâ üzerinde çalışılmaktadır.

Yukarıda yapılan açıklamalar doğrultusunda, araştırma kapsamında incelenen 16 (onaltı) işletmenin belli başlı dijital insan kaynakları uygulamaları aşağıdaki gibi özetlenebilir:

- Insan Kaynakları'na gelen soruların cevaplanmasında Chatbotlarının kullanımı,

- $\quad$ İşe alım süreçlerinin tamamen dijital olarak yürütülmesi,

- $\quad$ işe alım süreçlerinde video ve online mülakatların yapılması,

- İşe alımlarda ön elemelerin yapay zekâ tarafından yapılması,

- Iş̧ başvurularının internet üzerinden $Q R$ kodla ya da bir linkle oluşturulan başvuru formunun kullanılarak gerçekleştirilmesi,

- Çalışanların izin, e-bordro gibi taleplerini mobil uygulama üzerinden gerçekleştirmeleri ya da dokümanlara mobil uygulama üzerinden ulaşabilmeleri,

- Takdir ve ödüllendirmelerin dijital platformdan yapılması,

- Tüm ík süreçlerinin mobil uygulamalara taşınması,

- Mobil uygulama desteği ile oryantasyon eğitimi yapılması,

- Dijital eğitim programlarının gerçekleştirilmesi,

- Dijital ödüllendirme sistemlerinin uygulanması,

- Mobil uygulama desteği ile çalışanlara online geri bildirim verilmesi,

- Dashboard ile veriye dayalı analizler, raporlamalar yapılabilmesi,

- Kadro hesaplamaları ve raporlamaların dijital ortamda yapılması,

- Performans yönetimi, terfi, tayin, çıkış vb. kariyer yönetimindeki iş süreçlerinin tamamen online ortamda gerçekleştirilmesi,

- Performans ve çalışan bağııık analizleri ve değerlendirmelerinin mobil çözümlerle anlık olarak yapılması

- Online staj programı gerçekleştirilmesi,

- Işsletme ile ilgili bilgilerin ve duyuruların çalışanlara mobil uygulamalar aracılığı ile hızılı bir şekilde ulaştırılması, 
- Yapay zekâ özellikli platform sayesinde kurum içinde işlerin yanı sıra projeler ve mentörlük fırsatları da paylaşılabilmesidir.

\section{SONUÇ}

Insan Kaynakları Yönetimi günümüzde yaşanan dijital dönüşümden en çok etkilenen alanlardan birisi haline gelmiştir. Dijital teknolojiler insan kaynakları uygulamalarına entegre edilmekte ve bu sayede bir çok yenilik ortaya çıkmaktadır. Örneğin, yapay zekalı robotların çalışan seçim ve mülakatlarında kullanılması ile binlerce aday arasından işletme politika ve beklentilerine uygun adayların belirlenmesi çok daha hızı ve maliyet ve zaman açısından tasarruflu bir şekilde gerçekleştirilebilmektedir. Aynı şekilde bordro, izin, rapor gibi rutin işlerin dijital ortamlarda gerçekleştirilmesi hem maliyet hem de zaman tasarrufu sağlamaktadır. Online gerçekleştirilen eğitimler çalışanların hem gelişimini desteklemekte hem de çalışan bağlılı̆ını olumlu yönde etkilemektedir. Turulja ve Bajgoric, (2016: 43), bilgi teknolojilerinin insan kaynakları uygulamaları ile birlikte kullanıldığında işletmelerin başarılarını olumlu yönde etkilediğini bulmuşlardır.

Insan Kaynaklarında dijitalleşmenin etkisiyle rutin işler dijitalleştiği için insan kaynakları çalışanları stratejik IK, kariyer planlama, çalışan bağııı̆ı gibi konulara daha fazla kaliteli vakit ayırabilmektedirler. Bu durum insan kaynakları çalışanlarının verimliliğine de olumlu katkı sağlamaktadır.

Dijitalleşmenin insan kaynakları üzerindeki en önemli etkilerinden birisi de esnek çalışmaya imkân tanımasıdır. Zamana ve mekana bağlı kalmadan online platformlar aracılığı ile hem çalışanlar işlerini gerçekleştirebilmekte hem de yöneticiler takip ve kontrollerini yapabilmektedirler. Bu durum dijitalleşmenin, hem maliyet tasarrufu hem de çalışan memnuniyeti açısından işletmelere olumlu bir katkısıdır.

Sonuç olarak, günümüzde teknolojik gelişmeler iş yaşamında dijitalleşmeye ve dijital bir dönüşüme yol açmaktadır. İnsan kaynakları yönetimi ve uygulamaları bu dijital dönüşümden oldukça fazla etkilenmektedir. Neredeyse tüm insan kaynakları uygulamaları dijital ortamlarda ve dijital araçlar ile gerçekleştirilebilmektedir. Tüm işletmelerin bu değişim ve dönüşümün farkında olarak kendi işletmelerinin insan kaynakları uygulamalarını yaşanmakta olan bu dijital dönüşüme uyarlaması gerekmektedir.

\section{KAYNAKLAR}

Aktaş News (2018). Ocak-Şubat-Mart, 13. Sayı.

Alçın, S. (2016). Endüstri 4.0 ve İnsan Kaynakları, Ekonomi ve Insan Popüler Yönetim Dergisi, 63: 46-47.

Asiltürk, A. (2018). İnsan Kaynakları Yönetiminin Geleceği: İ 4.0, Journal of Awareness, 3(özel): 527-544.

Aydem Çiftçioğlu, B.; Mutlu, M. ve Katırcıoğlu, S. (2019). Endüstri 4.0 ve İnsan Kaynakları Yönetiminin İlişkisi, Sosyal Bilimler Araştırmaları Dergisi, 2(1): 31-53.

Betchoo, N. K. (2016). Digital Transformation and its impact on Human Resource Management, IEEE International Conference on Emerging Technologies and Innovative Business Practices for the Transformation of Societies (EmergiTech): 1-6.

Celep, M. ve Afacan Fındıklı, M. (2018). Elektronik İnsan Kaynakları Uygulamalarının Örgütsel Çıktılar Üzerindeki Etkileri: Türkiye'de Yabancı Iştirakli Sigorta Şirketlerinde Bir Araştırma, Beyder, 13(1): 63-77.

Chulanova, Z. K. (2019). Professional Standards as a Factor of Adaptation of Human Resources to the Industry 4.0: Approaches to Development and Implementation, Journal of Human Resource Management, 22(1): 12-20.

Demir, A. O. (2019). Digital Skills, Organizational Behavior and Transformation of Human Resources: A Review, Ecoforum, 1(18): 1-6.

Fenech, R.; Baguant, P. ve Ivanov, D. (2019) The Changing Role of Human Resource Management in an Era of Digital Transformation, International Journal of Entrepreneurship, 22(2): 166-175.

Garbelli, M. (2020). Digital Revolution in Small and Medium Enterprises'Human Resources: The Case of Brescia, European Scientific Journal, 16(7): 24-49.

Göktaş, P. ve Baysal, H. (2018). Türkiye'de Dijital İnsan Kaynakları Yönetiminde Bulut Bilişim, Süleyman Demirel Üniversitesi Iktisadi ve Idari Bilimler Fakültesi Dergisi, 23(4): 1409-1424.

Pağda, Z. (2019). Dijital Transformasyon ve İnsan Kaynaklarına Etkisi, Harvard Business Review Türkiye, 09.04.2019.

Seçer, H. Ş. (2017). İnsan Kaynakları Alanına Bloglar Üzerinden Bakmak Nitel Bir İnceleme, Yönetim ve Ekonomi: Celal Bayar Üniversitesi Iktisadi ve idari Bilimler Fakültesi Dergisi, 24(3): 759-782. 
Şendoğdu, A. A. (2020). Endüstri 4.0 Devriminde Robotik Kaynaklar Yönetimi Bağlamında İnsan Kaynakları Yönetiminde Yeni Açılımların Kaçınılmazlığı, Atatürk Üniversitesi Iiktisadi ve Idari Bilimler Dergisi, 34(1): 168-184.

Tataru, C. (2019). Human Resources in the Digital Age A Manager's Realities and Perspectives, Review of International Comparative Management, 20(4): 473-480.

Turulja, L. ve Bajgoric, N. (2016). Human Resources or Information Technology: What is More Important for Companies in the Digital Era? Business Systems Research, 7(1): 35-45.

Yalçın Kayıkçı, M. ve Kutluk Bozkurt, A. (2018). Dijital Çağda Z ve Alpha Kuşağı, Yapay Zeka Uygulamaları ve Turizme Yansımaları, Sosyal Bilimler Metinleri, 1: 54-64.

https://www.capital.com.tr/yonetim/insan-kaynaklari/ikda-dijital-donem, Erişim Tarihi, 26.03.2020.

https://www.akbank.com/tr-tr/sayfalar/default.aspx, Erişim Tarihi, 30.03.2020.

https://www.finans365.com/bankacilik/akbank-kobi-lerin-insan-kaynaklari-yonetimini-dijital-dunyaya/11008/, Erişim Tarihi, 30.03.2020.

http://fintechtime.com/tr/2017/12/akbank-ve-kolay-ik-kobilerin-ik-yonetimini-dijitale-tasiyor/, Erişim Tarihi, 30.03.2020.

https://www.bloomberght.com/teknoloji-ve-ik-da-mukemmellik-akbank-in-gelecegi-2229094, Erişim Tarihi, 30.03.2020.

https://www.milliyet.com.tr/yerel-haberler/ankara/akbank-ve-kolay-ik-kobilerin-ik-yonetimini-dijitale-tasiyor-12449371, Erişim Tarihi, 30.03.2020.

https://www.capital.com.tr/capital-dergi/genc-capital-433671/ikyi-yeniden-tasarladik, Erişim Tarihi, 30.03.2020.

https://www.akbanklab.com/tr/guncel/basinda-biz/akbank-ve-kolay-ik-kobilerin-ik-yonetimini-dijitale-tasiyor, Erişim Tarihi, 06.05.2020.

https://www.abdiibrahim.com.tr/, Erişim Tarihi, 06.05.2020.

https://www.hurriyet.com.tr/ik-yeni-ekonomi/ise-alimi-dijitallestirdi-40487460, Erişim Tarihi, 06.05.2020.

https://www.capital.com.tr/yonetim/insan-kaynaklari/yeni-ik-gercekleri?sayfa=3, Erişim Tarihi, 06.05.2020.

http://www.turkchem.net/abdi-ibrahime-insana-degerde-liderlik-odulu.html, Erişim Tarihi, 06.05.2020.

https://www.borusan.com/tr/anasayfa, Erişim Tarihi, 06.05.2020.

https://magg4.com/nursel-olmez-ates-insan-kaynaklarinin-bugunu-ve-gelecegi-uzerine/, , Erişim Tarihi, 06.05.2020.

https://hrdergi.com/calisanlar-sayesinde-basari-ya-kosarken-3y-surekli-hayatimizin-merkezinde, Erişim Tarihi, 06.05.2020.

https://www.bsh-group.com/tr/, Erişim Tarihi, 04.05.2020.

https://hrdergi.com/kusaklari-goz-onune-alarak-ik-uygulamalari-sunmaya-devam-edecegiz, Erişim Tarihi, 04.05.2020.

http://blog.bsh-group.com.tr/makale/ik-mudurumuz-ahmet-aksoyun-hr-dergisi-kasim-2014-sayisinda-yayinlanan-roportaji, Erişim Tarihi, 04.05.2020.

https://www.denizbank.com/, Erişim Tarihi, 07.05.2020.

https://ikmagazin.com/insan-kaynaklari/denizbank-insan-kaynaklarina-odul/, Erişim Tarihi, 07.05.2020.

https://hrdergi.com/deniz-de-dijital-insan-kaynaklari-uygulamalari, Erişim Tarihi, 07.05.2020.

https://www.haberler.com/denizbank-a-insan-kaynaklari-alaninda-iki-odul-9851478-haberi/, Erişim Tarihi, 07.05.2020.

https://www.dogusotomotiv.com.tr; Erişim Tarihi, 01.05.2020.

http://www.odd.org.tr/web_2837_1/entitialfocus.aspx?primary_id=1645\&target=categorial1\&type=32\&detail=single, Erişim Tarihi, 01.05 .2020$. https://www.lojiyol.com/dogus-otomotivde-dijital-donusum-departmani-kuruldu/, Erişim Tarihi, 01.05.2020.

https://www.hurriyet.com.tr/ik-yeni-ekonomi/ik-altyapilarini-bayilere-yaydilar-40386347, Erişim Tarihi, 01.05.2020.

http://www.dogusotomotiv.com.tr/faaliyet-raporu-2019/insankaynaklari.html, Erişim Tarihi, 01.05.2020.

https://www.mercedes-benz.com.tr/passengercars.html?group=all\&subgroup=see-all\&view=BODYTYPE, Erişim Tarihi, 05.05.2020.

https://www.hurriyet.com.tr/ik-yeni-ekonomi/gencler-yoneticilere-mentorluk-yapti-41136897, Erişim Tarihi, 05.05.2020.

https://www.migros.com.tr/, Erişim Tarihi, 02.05.2020. 
https://www.aa.com.tr/tr/sirkethaberleri/hizmet/ise-alimda-dijital-is-gucu-donemi-baslatan-carrefoursaya-3-odul/650273, Erişim Tarihi, 02.05.2020.

https://hrdergi.com/soru-cevap-ik-yonetici-anketi-2269, Erişim Tarihi, 02.05.2020.

https://www.pg.com.tr/, Erişim Tarihi, 09.05.2020.

https://www.hurriyet.com.tr/ik-yeni-ekonomi/cesitlilige-cok-acigiz-41021814, Erişim Tarihi, 09.05.2020.

https://hrdergi.com/30-yasinda-ve-artik-daha-esnek-bir-liderler-okulu-p-g-turkiye; Erişim Tarihi, 09.05.2020.

https://www.pepsico.com.tr/, Erişim Tarihi, 07.05.2020.

https://www.hurriyet.com.tr/ik-yeni-ekonomi/iknin-gelecegi-buyuk-veride-40423034, Erişim Tarihi, 07.05.2020.

https://www.kariyer.net/ik-blog/pepsico-hr-venueyu-anlatiyor/, Erişim Tarihi, 07.05.2020.

https://www.peryon.org.tr/Akif-Yumuk, Erişim Tarihi, 07.05.2020.

https://www.sabancidx.com, Erişim Tarihi, 04.05.2020.

https://www.turkishtradenews.com/sabancidx-hr-web-ile-avrupanin-en-iyi-10-listesinde-yer-aldi.html, Erişim Tarihi, 04.05.2020.

https://kariyer.sabanci.com/tr/insan-kaynaklari-politikalari, Erişim Tarihi, 04.05.2020.

https://www.se.com/tr/tr/, Erişim Tarihi, 09.05.2020.

https://hrdergi.com/schneider-electricin-tum-enerjisi-dijitallesmede, Erişim Tarihi, 09.05.2020.

https://www.hurriyet.com.tr/teknoloji/schneider-electric-endustri-4-0-zirvesinde-deneyimlerini-paylasti-41372014, Erişim Tarihi, 09.05.2020.

https://hrdergi.com/dijitalleserek-ve-yalinlasarak-2020-vizyonuna-hazirlaniyoruz, Erişim Tarihi, 09.05.2020.

https://www.hurriyet.com.tr/ik-yeni-ekonomi/dijital-donusumde-ikya-onemli-gorev-40582282, Erişim Tarihi, 09.05.2020.

https://www.se.com/tr/tr/about-us/press/press-release/2018-press/schneider-electric-leads-the-global-arena.jsp, Erişim Tarihi, 09.05.2020.

https://www.tabgida.com.tr/, Erişim Tarihi, 01.05.2020.

https://www.yasar.com.tr/tr/, Erişim Tarihi, 06.05.2020.

https://www.yildizholding.com.tr/, Erişim Tarihi, 10.05.2020 